\title{
TWO-SIDED MARKETS AND ELECTRONIC INTERMEDIARIES
}

\author{
BRUNO JULLIEN
}

\section{CESIFO WORKING PAPER NO. 1345}

CATEGORY 9: INDUSTRIAL ORGANISATION

NOVEMBER 2004

Presented AT CESIFo ECONOMIC STUdies CONFERENCE ON UNTERSTANDING THE DigitAl ECONOMY: FACTS AND THEORY, JULY 2004

\footnotetext{
An electronic version of the paper may be downloaded

- from the SSRN website: www.SSRN.com

- from the CESifo website: www.CESifo.de
} 


\title{
TWO-SIDED MARKETS AND ELECTRONIC INTERMEDIARIES
}

\begin{abstract}
The object of this paper is to discuss on-line intermediation from the perspective of two-sided markets. It builds a simple model of the intermediation activity when trading partners are involved in a commercial relationship and uses it to illustrate some of the results that emerge in the two-sided market literature, as well as to discuss some new aspects. The first part concentrates on a monopoly intermediation service and discusses both efficient pricing and monopoly pricing. The second part discusses the nature of competition between intermediaries, addressing issues as competitive crosssubsidies, multi-homing or tying.

JEL Code: D4, D85, L12, L13, L14, L40.
\end{abstract}

Keywords: intermediation, two-sided market, network, cross-subsidy, tying.

\author{
Bruno Jullien \\ University of Toulouse \\ IDEI \\ Manufactures de Tabacs, Bat F \\ 21, Allée de Brienne \\ 31000 Toulouse \\ France \\ bjullien@cict.fr
}

The author thanks Carole Haritchabalet, Monika Schnitzer and participants at the CESIfo conference "Understanding the Digital Economy", and at the IDEI conference "The Economics of Electronic Communications Markets" for valuable comments. 


\section{Introduction}

Some of the major innovations associated with digital communication technologies concern the process of intermediation (see for instance the survey on electronic commerce in The Economist (February 2000)). Traditional brick and mortar intermediation provides several services in an integrated system. It manages various information flows. It provides physical facilities for the exchange process (transport, storage, exhibition). Digital technologies leads to separate these two types of functions, exploiting the drastic reduction in the cost of information processing and of telecommunications associated with NTIC. It thus becomes important to understand how a sector specialized in information management can organized itself. We refer to this activity as info-mediation. A key characteristic of on-line info-mediation is that it incurs very small variable costs.

Considering at a general level the intermediation activity on-line, one find two main functions that are performed: a) identify profitable trade opportunities, b) help to determinate the precise terms of trade. There are also numerous other information services that the intermediary can propose and that are derivatives of these two base functions (advice, billing, accounting, stock/flow management...). To this respect on-line intermediation offers a wide range of possibilities. Some sites such as Zdnet are specialized in providing information on products, sellers or prices ${ }^{1}$. In BtoB one tendency is to start with a simple matching service offered to a particular industry to move toward offering a full supply chain management service. ${ }^{2}$ Websites like eBay or Priceline offer the two services at a disaggregated level. ${ }^{3}$

Despite their diversity, most of these activities have in common that a key determinant of the value of the service is the size of potential trading partners that an agent can reach. ${ }^{4}$ Although there were already some consideration

\footnotetext{
${ }^{1}$ Nextag for instance proposes a search engine to compare products and prices over all funishers.

${ }^{2}$ Examples are Sciquest for life sciences, or eSteel for steel constructions. VerticalNet is an example of on-line supply management not specialised on a particular industry.

${ }^{3}$ eBay allows the sellers to choose the auction format within a menu. Priceline is an airline ticket reservation service that allows clients to post a destination and a desired price, letting the airlines react to the clients' offers.

${ }^{4}$ There are other externalities involved that are ignored in this paper. In particular the terms of trade may be affected by the degree of concentration on each side of the market, one side benefiting from being concentrated.
} 
about these aspects in the analysis of traditional intermediation ${ }^{5}$, recent work on various related domains have contributed to highlight the two-sided nature of the intermediation activities (see Rochet and Tirole (2004a)) for a general presentation).

At the intuitive level, the concept of two-sided markets refer to situations where one or several competing "platforms" provide services that are used by two types of trading partners to interact and operate an exchange. Examples of two-sided markets that differ from on-line intermediation include

- Payment card systems. ${ }^{6}$ Here the two sides of the markets are merchants and buyers who conduct a transaction and use the card as a mean of payment.

- Shopping malls. ${ }^{7}$ Here the two sides of the markets are merchants and buyers.

- Video game console: the seller of the technology offers a platform on which developers offer video games to consumers. It charges consumers for the console, and royalties to developers.

The literature then emphasizes the indirect network effects ${ }^{8}$ involved in these activities. These effects generate a well known chicken\&egg problem: a customer on one side of the market will be willing to participate to the platform activity only if he expects a sufficient participation from the other side. In such a context platforms are going to offer a price structure which may include prices that agents have to pay if their want to participate to the activity of the platform (registration or membership fees), as well as prices related to the level of activity on the platform such as transaction fees that are payed once an exchange takes place. The platform will have to account for the demand externalities when designing the price structure. To this extent the literature on monopoly platforms is related to the literature on the multi-product firm, where the goods are complements. On the other hand the literature on competing platforms is more related to the literature on competing networks.

\footnotetext{
${ }^{5}$ See for instance Yanelle (1989).

${ }^{6}$ See Rochet and Tirole (2002)

${ }^{7}$ See Pashigan and Gould (1998).

${ }^{8}$ See Katz-Shapiro $(1985,1986)$ and Farell-Saloner $(1985,1986)$.
} 
The objective of this paper is to build a simple model of the intermediation activity when trading partners are involved into a commercial relationship and to use it to illustrate some of the results that emerge in the two-sided market literature, as well as to discuss some new aspects. The first part concentrates on a monopoly intermediation service and discusses both efficient pricing and monopoly pricing. The second part builds on Jullien and Caillaud (2003) to discuss the nature of competition between platforms.

\section{The model}

The model is adapted from the one introduced in Gaudeul and Jullien (2001). Consider a service provider that intermediates the transactions between consumers and producers. A mass of consumers can buy electronic goods from independent producers on the web. There is a continuum of producers that can potentially sell these products through the web. Each producer is seen as selling a different product.

The intermediary provides a service that helps consumers to find a product. Firms and consumers register to the intermediary. Then consumers can get access to the list of products, characteristics and prices, and the service assists them in identifying their match if it is registered. Accessing to this search technology involves an opportunity cost for the consumer (because of complexity, inadequate search process, delay). This cost can also be seen as the value for the consumer of using an alternative technology to find a trading partner. Let $F(c)$ be the mass of consumers with an opportunity cost less than $c$. Each firm faces a fixed cost of providing the good through the platform. The products are ranked by increasing order of fixed cost and the mass of producers with a fixed cost below some level $k$ is $H(k)$. Normalize by assuming that the total population is 1 on each side and that all other costs are zero. In what follows it will most often be assumed that these distributions are continuous with a corresponding densities $h(k)$ and $f(c)$, although the key results hold for arbitrary distributions.

Let $m$ be the mass of producers on the intermediary service, and $n$ be the mass of consumers. Assume that each consumer has a probability to have a trading partner on the platform equal to the mass $m$ of producers. Let $P$ be the probability that a trade occurs between two trading partners when they are both active on the platform (this requires that the two partners are matched and find an agreement). The total volume of transaction generated 
by the platform is $V=n m P$, where $m n$ is the number of potential pairs of partners. Denote by $s$ the expected surplus of a consumer conditional on having a potential trading partner on the platform, then the expected surplus that a consumer derives from participating to the platform process is $m s-c .^{9}$ The expected surplus $s$ accounts for both the probability that a trade occur $(P)$, and for the expected value generated by the exchange. Similarly, $\pi$ is the expected profit per consumer (ignoring the fixed cost $k$ ) that a producer derives from his participation, so that the surplus of the producer is $n \pi-k$. Again $\pi$ is the product of $P$ and of the expected profit per transaction.

The instruments of the intermediary

In this set-up, the financial resources that the intermediary can use to finance its activities depend what is observed.

- Registration fees: The intermediary may impose registration fees $p$ for consumers and $q$ for the producers. This requires that participation can be monitored at a low cost, and that micropayment are not too costly. This is satisfied in most BtoB activities, but in some BtoC or CtoC activities it too costly to charge the participation of consumers, at least before a match is performed.

- Transaction fees: The intermediary may charge transaction fees $t_{C}$ and $t_{P}$ for respectively the consumers and the producers. This requires to monitor transactions. In some case only one side of the market may be charged. When intermediation leads to some commercial transactions with a transfer negotiated between the two parties and only transactions can be monitored (not matches), only the total fee $t=t_{u}+t_{D}$ matters, as the producer will adjust its price to any rebalancing of the fees between the two parties. Thus in this case again only one fee can be considered. Denote by $T$ the set of feasible transaction fees. The expected surplus of producers is then $\pi=\pi(t)$, while the consumers surplus is $s=s(t)$, and the volume of transaction is $P(t) m n .{ }^{10}$ Typically $\pi(t)+s(t)$ decreases with $t$.

\footnotetext{
${ }^{9}$ Notice that consumers differ ex-ante only by their opportunity cost $c$. The trading surplus may vary ex-post (once the trading partner is found) but in expected terms, it is the same for all consumers ex-ante.

${ }^{10} \mathrm{~A}$ simple model goes as follows. At the time they choose to access the service, consumers do not know which products they will be willing to buy. They connect to the web, and only after, each consumer draws randomly a single product that she wishes to
} 
- Advertising: advertising is a way to finance the activity that can be analyzed using the multi-sided market approach. ${ }^{11}$ It will not be considered here.

- Bundling with information goods: One way to attract customers is to include the intermediation service in a bundle with other information services that are not affected by network externalities. This includes the activities of portals, but also billing, accounting or any other information services for BtoB.

\section{$3 \quad$ Externalities and surplus}

\subsection{Registration fees and participation externalities}

Assume for the moment that the intermediary just use registration fees, so that $T=\{0\}$. The surplus $s$, the profit $\pi$ and $P$ are thus exogenous. The profit of a producers with an entry cost $k$ is $n \pi-q-k$ and the expected surplus of a consumer with an opportunity cost $c$ is $m s-p-c$. A producer joins the platform if $k \leq n \pi-q$, while a consumer joins if $c \leq m s-p$. We thus obtain:

$$
\begin{aligned}
m & =H(n \pi-q), \\
n & =F(m s-p),
\end{aligned}
$$

The two-sided nature of the market is embedded in the fact that the demand addressed by one side of the market depends on the demand on the

consume (her valuation being 0 for the others). At this stage she does not know yet what will be her precise valuation for the good nor its price. Then she has to find whether the product is available, what are its precise characteristics and its price. For this she has access to the search technology of the intermediary.

Once the match is done, the consumer observes her final valuation $w$ for the good as well as the price quoted by the producer. The distribution of $w$ determines a demand function $D($.$) for the good that is assumed to be the same for all goods. Given that all consumers$ are alike at the time the producers decide on the price and that consumers learn the price and $w$ only after the search process is completed, producers will choose the price $\hat{p}(t)$ net of $t_{P}$ that maximizes $\hat{p} D(\hat{p}+t)$. Let $\lambda$ be the probability that a match is performed when the pair is present, then the expected participation profit is $\pi(t)=\lambda \hat{p}(t) D(\hat{p}(t)+t)$, while $s(t)$ is equal to $\lambda \int_{\hat{p}(t)+t}^{\infty} D(w) d w$ and $P(t)=\lambda D(\hat{p}(t)+t)$.

${ }^{11}$ See Ferrando, Gabsewitcz, Laussel and Sonnac (2003), Anderson and Coate (2003), or Crampes, Haritchabalet and Jullien (2003). 
other side. Combining the two equations we find that the mass of consumers joining the platform is solution of the reduced form equilibrium condition:

$$
n=F(H(n \pi-q) s-p) .
$$

The volume of trade $V$ is then proportional to the product of the market shares on the two sides: $V=m n P=H(n \pi-q) n P$.

The model thus involves an indirect network externality between consumers: although consumers are not directly affected by other consumers, in equilibrium, each consumer creates a positive externality on the others through its impact on the producers' participation. ${ }^{12}$ The reduced form is then similar to a model of network externality. This type of externalities are referred to as "membership externalities" in Rochet and Tirole (2003).

The model may thus exhibit multiple equilibria and inefficiencies. In what follows we focus on stable equilibria where stability refers to a dynamic adjustment process where the two sides alternate in their registration choice and respond myopically to the other side market share.

As this is not the object of the paper we shall assume that there exist at most one equilibrium with a positive level of activity. This the case for instance if $F$ and $H$ are concave and bounded on $[0,+\infty[$. This is also the case if the two distribution $H$ and $F$ are Dirac, with $H(\pi)=F(s)=1$. In both cases, there can be at most one equilibrium with positive activity as $F(H(n \pi-q) s-p)$ can cross the diagonal with a slope less than one (stability) only once.

It is immediate to see that with positive prices $p$ and $q$, there always exists an equilibrium where no agent register. This is because no agent would pay to register if he anticipates that the other side refuses to get "on board".

A key point for what will follow is that for negative consumer registration fee $p$, and provided that $q<F(-p) \pi$, no activity is not an equilibrium and thus there exists a unique equilibrium allocation and it involves a positive activity on the platform.

Consider now an allocation with positive demands on both sides. Denote

$$
\theta=\pi s f(m s-p) h(n \pi-q)
$$

\footnotetext{
${ }^{12}$ Notice that intermediation may involve also direct negative externalities. For instance when sellers compete on the platform, the presence of an additional seller increases the competitive pressure and reduces the expected profit of other sellers (see for instance Baye and Morgan (2001) or Belleflamme and Toulemeonde (2004)).
} 
Assuming differentiability, the system of demand functions verifies

$$
\begin{aligned}
\frac{d m}{d q} & =-\frac{h(n \pi-q)}{1-\theta}, \\
\frac{d n}{d p} & =-\frac{f(m s-p)}{1-\theta}, \\
\pi \frac{d n}{d q} & =s \frac{d m}{d p}=-\frac{\theta}{1-\theta} .
\end{aligned}
$$

An increase in the price $q$ leads to a direct reduction $h$ of the mass of producers. This induces an adverse effect on the participation of consumers, and through the externality, a further reduction $\theta h$ of $m$, and so on. The overall multiplier effect associated with this feedback effect is $\frac{1}{1-\theta}=\Sigma_{s=0}^{+\infty} \theta^{s}$. The coefficient $\theta$ thus captures the feedback effect. Total surplus then writes as

$$
W=\left(m n s-\int_{0}^{m s-p} c d F(c)\right)+\left(m n \pi-\int_{0}^{n \pi-q} k d H(k)\right) .
$$

The brackets separate the consumers' surplus and the producers' surplus. The link between the two sides of the market is captured first by the product term $m n$ in both surpluses. Thus:

$$
W=m n(s+\pi)-\int_{0}^{m s-p} c d F(c)-\int_{0}^{n \pi-q} k d H(k) .
$$

The term $\pi+s$ is the total expected surplus per pair of partners, while $m n$ is the number of pairs. The other two terms are the opportunity costs of the agents joining the platform. Differentiating the surplus yields after some computation:

$$
\begin{aligned}
\frac{d W}{d q} & =(q+n s) \frac{d m}{d q}+(p+m \pi) \frac{d n}{d q} \\
\frac{d W}{d p} & =(q+n s) \frac{d m}{d p}+(p+m \pi) \frac{d n}{d p}
\end{aligned}
$$

To understand the formula, consider first the term $q+n s$. For a fixed demand size $n$, subsidizing entry of producers creates a distortion as in a competitive market: this is captured by the term $q$ equal to the gross surplus of the marginal producer. This distortion vanishes at $q=0$. Therefore for a fixed consumers' participation the optimal price would be equal to the marginal 
costs of servicing producers . But inducing more entry of producers also benefits directly to consumers since it increases their chance to find their desired product. The value of this externality is $s$ par consumer, hence the term $n s \frac{d m}{d q}$. The last term then accounts for the demand externalities and the fact that reducing the price $q$ also raises the participation of consumers.

Lemma 1 A small subsidy on each side of the market is welfare improving compared to the case where prices are equal to marginal cost.

To interpret further the results denote

$$
x=m s-p ; y=n \pi-q
$$

the surplus gross of opportunity cost of a participant on each side of the market. Then

$$
W=F(x) H(y)(\pi+s)-\int_{0}^{x} c d F(c)-\int_{0}^{y} k d H(k) .
$$

From this formula it is immediate that welfare maximization requires to set $x=H(y)(\pi+s)=m(\pi+s)$ and $y=n(\pi+s)$. The interpretation is straightforward. Consumers should participate as long as their opportunity cost is smaller than the total surplus generated by their participation, which includes their surplus $m s$ but the also the positive externality on the other side of the market $m \pi$ ( $\pi$ for each of the $m$ producers).

Thus welfare maximizing prices will not coincide with marginal costs to account for externalities. Indeed optimality will call for subsidies. More precisely, provided that demand are not inelastic, welfare maximizing prices verify (using $p=m s-x$ and $q=n \pi-y$ ):

$$
\begin{aligned}
& q=-n s \\
& p=-m \pi
\end{aligned}
$$

Proposition 2 (Armstrong (2004)) The welfare maximizing registration subsidy to producers is equal to the total consumers' surplus per producer; the welfare maximizing registration subsidy to consumers is equal to the total expected producers' profit per consumer.

One view about this result is that one should subsidize more the less profitable side of the market. 
Notice that, as all the producers benefit, they have a collective interest in subsidizing the entry of consumers. So even in the absence of government intervention, the market may organize so as to provide incentives to entry. In particular, when introducing intermediation, intermediaries may internalize this effect through their pricing policies. The question will then be whether intermediaries have proper incentives to do so.

\subsection{Transaction fees}

Let us now allow for transaction fees. To simplify, tax neutrality is assumed so that only the total transaction fee is allowed. Let $s(t)$ be the per producer expected surplus of a consumer, and $\pi(t))$ be the per consumer expected profit of a producer.

For a given price structure the allocation now verifies

$$
\begin{aligned}
m & =H(n \pi(t)-q) \\
n & =F(m s(t)-p)
\end{aligned}
$$

while the volume of trade is $V=m n P(t)$.

An increase in the transaction fee has two effects. First for a given volume of trade it affects negatively the trading parties' surplus. Here this is captured by the fact that $\pi^{\prime}(t) \leq 0$ and $s^{\prime}(t) \leq 0$. Second it affects the volume of trade on the platform for a given participation level: $P^{\prime}(t) \leq 0$. Denote

$$
S(t)=s(t)+\pi(t)+P(t) t
$$

the expected total surplus from a pair of partners. Then typically $S(t)$ is non-increasing in $t$ in the range of positive transaction fees.

An increase in the transaction fee leads to a reduction in participation as the net profit and the net consumers surplus decrease:

$$
\frac{d m}{d t} \leq 0 ; \frac{d n}{d t} \leq 0 .
$$

Let us now consider welfare maximization when transaction fees are used. Welfare writes as

$$
W=m n S(t)-\int_{0}^{m s(t)-p} c d F(c)-\int_{0}^{n \pi(t)-q} k d H(k) .
$$


Using as before $x=m s(t)-p$ and $y=n \pi(t)-q$ we find that

$$
W=m n S(t)-\int_{0}^{x} c d F(c)-\int_{0}^{y} k d H(k) .
$$

Notice that for any $t$, the platform can control the surpluses $x$ and $y$ through an adequate choice of registration fees. Thus the platform has enough instruments to control for both the volume of trade and the participation levels. Welfare maximizing prices must then verify

$$
\begin{aligned}
t^{W} & \in \arg \max _{t \in T}(\pi(t)+s(t)+P(t) t) \\
x^{W} & =m^{W}\left(\pi\left(t^{W}\right)+s\left(t^{W}\right)+P\left(t^{W}\right) t^{W}\right) \\
y^{W} & =n^{W}\left(\pi\left(t^{W}\right)+s\left(t^{W}\right)+P\left(t^{W}\right) t^{W}\right)
\end{aligned}
$$

The transaction fee should be used to correct for the inefficiency in the trade process. Typically, in the case of commercial transactions, there is a suboptimal level of trade so that the fee should be negative so as to induce efficient trade whenever this is feasible. ${ }^{13}$ A particular case that will be discussed later is one where the total surplus per match is not affect by the transaction fee, $S(t)=S$ for all $t \in T$ (this is the case for instance if the trading parties share a fixed surplus $S$ and $T=[0, S])$. Then the level of transaction fee can be anything provided that registration fees are adjusted consequently.

The last equations have the same interpretation as before: $x$ is the opportunity cost of the marginal consumer and should be equal to the total surplus generated by its participation. Then, using the definition of $x$ and $y$, we see that optimal registration fees verify:

$$
\begin{aligned}
& q^{W}=-n^{W}\left(s\left(t^{W}\right)+P\left(t^{W}\right) t^{W}\right) \\
& p^{W}=-m^{W}\left(\pi\left(t^{W}\right)+P\left(t^{W}\right) t^{W}\right)
\end{aligned}
$$

Typically, the registration fees may be negative to induce adequate internalization of the network effects by the participants.

\section{Usage externalities}

\footnotetext{
${ }^{13}$ Notice that a negative transaction fee may seem odds as it may induce parties to claim false matches and collect the fees. In this case we may conclude that the optimal transaction fee is zero in this case.
} 
The work of Rochet and Tirole (2003) focuses on the impact of the structure of transaction fees on the efficiency of trade, what they refer to as usage.

In their model, there is no registration cost, the terms of trade between the producers and the consumers are fixed and each side faces a fee $t_{U}$ or $t_{D}$. Then trade occurs whenever both parties derive a surplus larger than his fee, leading to a volume of trade proportional to the product $n\left(t_{C}\right) m\left(t_{P}\right)$ where $n\left(t_{C}\right)$ (resp. $m\left(t_{P}\right)$ ) is the mass of consumers (resp. producers) willing to trade at fee $t_{C}\left(\right.$ resp. $\left.t_{P}\right)$.

According to their terminology there is no two-sided aspect related to usage in the current model.

Definition 3 (Rochet and Tirole (2004a)): Assume no registration fees, the usage interaction on the platform is one-sided if the volume of transaction depends only on the aggregate transaction fee, i.e. is insensitive to the reallocation of this total fee between the consumer and the producer.

In the case of two-sided usage externalities, both the total transaction fee and its repartition between the parties matter for efficiency.

According to their definition our model is one sided if there is no registration fees, in particular it cannot involve cross-subsidies as only $t$ matters. Notice however that, by reducing the gains from trade, a tax on transactions also affects the participation levels. Increasing $t$ would also mean reducing participation of both sides of the market. In terms of externalities, it is then difficult to distinguish between one-sided or two-sided usage.

In other words, an increase in the transaction fee directly reduces the participation level of consumers which in turn reduces the expected gain of a producer participating to the platform. And the reverse holds for the participation of producers. In the case of participation externality, the determination of the usage fee must account for a two-sided dimension "mediated" through the participation levels.

As discussed in Rochet and Tirole (2004a), even in our context of tax neutrality, usage may be two-sided if the intermediary intervenes on the terms of trade either directly or through sophisticated tariffs such as a nonlinear fee. Suppose for instance that in addition to set transaction fees, the intermediary can monitor the transaction price $\hat{p}$ between the trading parties. Then it is optimal for the intermediary to use a direct control of the price $\hat{p}$, to raise the surplus from trade, as in Wright (2003), and then to use transaction 
fees $t_{C}$ and $t_{P}$ to recoup the profit and to control for the participation levels of both side. In this case usage will be two-sided.

\subsection{Ramsey pricing}

Notice that at the welfare maximizing prices profit $\Pi=-m n(s(t)+\pi(t)+P(t) t)$ is negative. The platform thus runs a deficit and should be subsidized. Consider now the case where the platform is benevolent but subject to a non negative profit condition. Here we may think of the platform as a cooperative jointly owned by the community of consumers and producers.

The profit of the platform is

$$
\begin{aligned}
\Pi & =m n P(t) t+p n+q m \\
& =m n S(t)-x n-y m
\end{aligned}
$$

Maximizing total surplus under zero profit yields the constrained optimal allocation. Optimal Ramsey prices are such that the transaction fee $t$ is set at the level that maximizes the surplus generated by each match $S(t)$, while registration fees are used to cover the fixed cost, as before.

To see that, let $\gamma$ be the shadow value of the budget constraint, the optimality obtains by

$$
\max _{t, x, y}\left(\operatorname{mnS}(t)-\int_{0}^{x} c d F(c)-\int_{0}^{y} k d H(k)+\gamma(m n S(t)-x n-y m)\right)
$$

st $n=F(x) ; y=H(y)$.

It is then immediate that the optimal transaction verifies as before

$$
t^{R} \in \arg \max _{t \in T}(\pi(t)+s(t)+P(t) t)
$$

In any case transaction fees should maximize the total surplus per match. The reason is that all efficiency gains in the trading process can be recoup through the transaction fees. ${ }^{14}$

\footnotetext{
${ }^{14}$ Clearly this results rellies on the fact that the expected surplus is the same for all trading pairs. Otherwise welfare maximization would call to maximize the average welfare from trade given the participation levels, while profit maximization will account for the surplus of the marginal consumers and producers.
} 
The participation levels are then given by

$$
\begin{aligned}
x^{R} & =m^{R} S\left(t^{R}\right)-\frac{\gamma}{1+\gamma} \frac{F\left(x^{R}\right)}{f\left(x^{R}\right)} \\
y^{R} & =n^{R} S\left(t^{R}\right)-\frac{\gamma}{1+\gamma} \frac{H\left(y^{R}\right)}{h\left(y^{R}\right)}
\end{aligned}
$$

corresponding to registration fees

$$
\begin{aligned}
& p^{R}=-m^{R}\left(\pi\left(t^{R}\right)+P\left(t^{R}\right) t^{R}\right)+\frac{\gamma}{1+\gamma} \frac{F\left(x^{R}\right)}{f\left(x^{R}\right)} \\
& q^{R}=-n^{R}\left(s\left(t^{R}\right)+P\left(t^{R}\right) t^{R}\right)+\frac{\gamma}{1+\gamma} \frac{H\left(y^{R}\right)}{h\left(y^{R}\right)}
\end{aligned}
$$

The results state that in order to balance the budget it is optimal to use the transaction fee to maximize the surplus conditional on participation and to rely on fixed payments for the financing. This is similar to an optimal two-part tariff rule and it is related to the fact that apart from the fixed cost of participation, all individuals are identical ex-ante. In a more general set-up one would rely on the all prices so that $t$ would be larger. Notice that in our model this implies that the platform runs a deficit on transactions

A second consequence is that whether the consumers or the producers will be subsidized depends on two considerations: how much surplus they create for the other side, and the elasticity of demand.

For instance suppose that there is no transaction fees, $T=\{0\}$. This corrersponds to the situation discussed in Armstrong (2004). The same logic applies where the benefits from trade are computed for $t=0$. Optimal registratiopn fees are given by:

$$
\begin{aligned}
p & =-m \pi+\frac{\gamma}{1+\gamma} \frac{F}{f} \\
q & =-n s+\frac{\gamma}{1+\gamma} \frac{H}{h} \\
0 & =p n+q m
\end{aligned}
$$

A simple computation would show that $p$ is negative if $s n \frac{n}{f}<\pi m \frac{m}{h}$, thus if a consumer exerts a relatively high externality compared to a producer, and consumers participation is very sensitive to the price. In this case, a slight reduction of the price $p$ is very beneficial as it leads to a large increase in the participation level of consumers and a high externality on producers. 


\section{Monopoly pricing}

Let us now consider the case of a monopoly intermediary. In what follows we shall contrast the case where the monopoly has access to a full set of instruments to various relevant scenarios. Unless stated we assume that there is no coordination problem so that the equilibrium with positive participation of both sides emerges.

The monopoly profit is equal to $\Pi=m n P(t) t+p n+q m$. When maximizing its profit, the monopoly will account for externalities through the impact of the participation level of one side on the willingness to pay on the other side. To follow the welfare analysis, denote as before $x=m s(t)-p$ and $y=n \pi(t)-q$. Then profit is given by $\Pi=m n S(t)-x n-y m$. Let us view the monopoly as choosing $x, y$ and $t$. Then the condition for $t$ writes

$$
t^{M} \in \arg \max _{t \in T}(\pi(t)+s(t)+P(t) t) .
$$

Thus, transaction fees should be set at a level that maximizes the total surplus generated by the transactions of a pair of customers. This is similar to the conclusion derived for instance by Rochet and Tirole (2004a) for the case where parties bargain over trade and a transaction price.

As in the case of Ramsey pricing, it serves the purpose of enhancing the surplus while the registration fees are used to share this surplus. As pointed above, the result is related to the two-part tariff literature and the fact that faced to an homogenous population, a monopoly would set a two-part tariff with a unit price equal to marginal cost (which maximizes the total surplus from consumption). Building on this literature one can then anticipate factors that would raise the transaction fee. For instance consumers or producers heterogeneity, or risk aversion ${ }^{15}$ may lead to higher transaction fees. Similarly if the surplus from trade is affected by the quality of intermediation, a positive transaction fee may help in providing adequate incentive to the intermediation platform. ${ }^{16}$

\footnotetext{
${ }^{15}$ With risk averse participants, a positive transaction fee may help in providing some insurance to the participants.

${ }^{16}$ Hagiu (2004) develops an argument along this line, where transaction fees are negative. Hagiu then examines a sequential pricing and participation game (producers than consumers). He points to the fact that running a deficit on transactions allow to raise the producers' registration fee but may hinder the incentives to attract consumers hereafter. The ability to commit on future prices for consumers then matters for the conclusion. Without such a commitment, transaction fees will be higher.
} 
The participation levels are then given by

$$
\begin{aligned}
& x^{M}=m^{M} S\left(t^{M}\right)-\frac{n^{M}}{f\left(x^{M}\right)} ; y^{M}=n^{M} S\left(t^{M}\right)-\frac{m^{M}}{h\left(y^{M}\right)} \\
& n^{M}=F\left(x^{M}\right) ; m^{M}=H\left(y^{M}\right)
\end{aligned}
$$

leading to registration prices

$$
\begin{aligned}
p^{M} & =\frac{n^{M}}{f\left(x^{M}\right)}-m^{M}\left(\pi\left(t^{M}\right)+P\left(t^{M}\right) t^{M}\right) \\
q^{M} & =\frac{m^{M}}{h\left(x^{M}\right)}-n^{M}\left(s\left(t^{M}\right)+P\left(t^{M}\right) t^{M}\right)
\end{aligned}
$$

For instance if the value of $m$ and $q$ were fixed, and $t=0$, the monopoly price on consumers would be $p=\frac{n}{f(x)}$. The monopoly price internalizes two other effects. First for $t$ different from zero, each new participant generates $m P(t) t$ additional income. Second, each new participant creates an externality that allows to raise the price on the other side of the market, by an amount $m \pi(t)$ for a constant other side's participation.

Our results imply that, whenever the surplus per match decreases with $t$ on the nonnegative range, transaction fees should be non-positive. Positive transaction fees could be motivated by some failure to charge registration fees. This is clearly the case if registration fees are two costly to implement on both sides. In other cases one side of the market is not charged at all (this is the case for portals or eBay). Now suppose that it is too costly to charge consumers (because they face transaction costs) but that transactions can be monitored $(p=0, t \neq 0)$. Then $x=m s(t)$, and it is not possible anymore to separate the determination of the surplus per match and the participation decision of consumers. Given that a positive transaction fee is passed through to the consumers, it is a way to force consumers to participate to the financing of the activity. Thus transaction fees may be substitutes for registration fees.

\section{Competing intermediaries}

\subsection{Competition with exclusivity}

From the preceding part, it appears that neither marginal cost pricing nor monopoly pricing would achieve an efficient allocation. One then wonders 
whether competition between two or more platforms can generate a more efficient allocation. So suppose now that there are two identical intermediation platforms, 1 and 2, that compete on the market. For the moment we concentrate on the case where consumers or producers can only register with one intermediary. This case is referred to as exclusivity. Notice that an efficient allocation in this set-up requires that all agents register with the same intermediary.

In such a context, due to network effects, the competitive pressure tends to favor the concentration of the activity on a single intermediation platform. For this discussion, I thus focus on equilibria where only one platform is active, the other only exerting a competitive pressure.

Caillaud and Jullien (2001, 2003) study a simplified version of this model. Their set-up assumes that the transaction fee is non-distortionary. In our setup we say that transaction fees are non-distortionary if there exists constants $S$ and $P$ such that:

- $S(t) \equiv S$ and $P(t) \equiv P$.

Thus neither the total surplus nor the probability of trade is affected by transactions fees. In this case both the optimal Ramsey transaction fee and the monopoly transaction fee are indeterminate. Their model assumes also that full taxation is possible, namely that $T=\left[0, \frac{S}{P}\right]$. Then by setting the maximal transaction fee the platform can appropriate the full surplus $P t=S$. They then set a competitive benchmark by showing that in this set-up the equilibrium involves zero profits. $^{17}$

Proposition 4 (Caillaud and Jullien (2003)) Assume that transaction fees are not distortionary and that full taxation is feasible, then any equilibrium involves a single active intermediary with zero profits.

To understand the result consider an equilibrium where all active agents register to the same platform, say platform $1 .{ }^{18}$ Let us denote as before $x=m s(t)-p$ and $y=n \pi(t)-q$ the total expected gross surplus and profit

\footnotetext{
${ }^{17}$ Their results as all results in this literature require some restrictions on the way consumers and producers select their platform. While there are many alternatives discussed in the literature, they would all lead to same conclusion for the competitive benchmark. Although important, these selection issues are rather concpetual and technical, so I leave them aside.

${ }^{18} \mathrm{~A}$ similar argument would show that two intermediaries cannot be active.
} 
for each side at the active platform. We thus have $n=F(x), m=H(y)$ and $\Pi=m n S-x n-y m$. Now suppose that $\Pi>0$. Then the inactive platform could simply set $t$ so that $P t=S$ (full taxation) and price $p=-x(-\varepsilon)$, $q=-y(-\varepsilon)$, where $\varepsilon$ is small and positive. Given that all the surplus from trade is taxed away, consumers would receive a utility from this competing platform that is independent from the other side participation level: $x(+\varepsilon)-c$ and larger than the equilibrium profit with the other platform. With these prices it is dominant for an agent to join the second platform if it registers somewhere. ${ }^{19}$ Thus $F(x)$ consumers would join, as well as $H(y)$. But doing so the inactive intermediary could obtain the intermediary profit $\Pi$. Thus it must be the case that the profit vanishes in equilibrium. We thus obtain a contestability result.

The second question is whether the equilibrium is efficient. In Caillaud and Jullien (2000), this is indeed the case as neither consumers nor producers face an opportunity cost to join the platform. $F$ and $H$ are just Dirac distributions so that a single platform with the whole population is efficient. Whether efficiency extends to the case of an elastic participation remains an open question. Clearly the efficient allocation will be one equilibrium, but it has to be shown whether it is the unique one.

\subsection{Distortionary transaction fees: divide and conquer}

The above reasoning depends on the assumption that transaction fees are non-distortionary which is very peculiar. Indeed the idea is that an intermediary can use the transaction fee to capture the full surplus generated by the platform, and the (negative) registration fees to redistribute this surplus and control for participation. For this type of strategy, it is essential to dispose of a non distortionary pricing instrument. So the relevance of the result may be somewhat limited in practice. One may then conjecture that as soon as $S(t)$ decreases with $t$, equilibria may involves positive profits.

To illustrate this let us assume that transaction fees are not available (Caillaud and Jullien, 2001). Then the most efficient competitive strategy takes the form of "divide and conquer". Again suppose that platform 1 serves the market alone at price $p$ and $q$. Suppose that the masses $n$ and $m$ of consumers and producers are fixed, $n=m=1$ (zero participation

\footnotetext{
${ }^{19}$ Remind that there is at most one allocation where a single platform serves the market at any price structure. Therefore a consumer cannot expect to have more than $m$ producers on a platform at the exhibited prices.
} 
costs). Then a strategy that allows platform 2 to capture the market takes the following form:

Divide: platform 2 sets a price $p_{2}=-x=p-s<0$

Conquer: platform 2 sets a price $q_{2}=\pi+\inf \{0, q\}$

A symmetric strategy can be used reverting the role of the two sides. The idea of the strategy is that the platform subsidies the consumers (or the producers) to convince them to join. Once the participation of one side of the market is obtained, this creates a bandwagon effect that allows the platform to recoup the subsidy through the registration fees payed by the other side of the market. At prices $p_{2}$, it is dominant for consumers to join platform 2. But, observing that, producers have the choice between: buying from platform 1 at price $q$ (if $q<0$ ), staying out (if $q>0$ ) or joining platform 2 and getting $\pi-q_{2}$.

This type of divide and conquer strategies are particular instances of more general strategies that emerge when networks compete and are able to price discriminate between users with different valuations of network effects. ${ }^{20}$ The networks will "buy" the participation of some types of users in order to create value for other users.

It is clear that in the context of competing intermediaries the choice of the best target for the subsidy accounts for two aspects:

- The group must be easy to divide, meaning that it is willing to separate from the others for a smaller subsidy than others;

- The group must be attractive for other participants, meaning that other agents are willing to pay a relatively large amount to join this group.

Thus consumers will be the natural target if $s<\pi$, so that they have less to gain than producers in the interaction.

These types of strategies allow to show, that despite network effects, there is limited scope for platform market power. Indeed in the simple case where $F$ and $H$ are Dirac at zero, if platform 1 is active in equilibrium, it must be the case that $p_{2}+q_{2} \leq 0$ or

$$
p+\inf \{0, q\}<s-\pi .
$$

\footnotetext{
${ }^{20}$ Jullien (2000) provides a treatment of a general competitive game between networks, allowing for asymmetric network effects and price discrimination
} 
Still, there is the possibility of market power and positive profits for the active platform. Indeed, from above we see that the profitability for platform 2 under the Divide and Conquer strategy is independent of the registration fee payed by producers whenever it is positive, $q>0$. The reason is that once platform 2 has convinced consumers to join, producers are no longer willing to pay this fee. The active platform may as well set $q$ large. ${ }^{21}$ Based on these arguments, Caillaud and Jullien $(2001,2003)$ show that there exist equilibria with a single active platform and positive profits. The result relies on very little restrictions being imposed on the way consumers and producers coordinate. One way out is to limit the potential extent of coordination failure due to network externalities by imposing additional restrictions on the process governing the allocation of consumers and producers between the two intermediation platforms. For instance, Ambrus and Argenziano (2003) restore zero profit for an homogeneous population by imposing some conditions limiting the extent of coordination failure. Gabszewitcz and Wauthy (2004) reaches a similar conclusion assuming passive expectation. ${ }^{22}$

In the most reasonable case where transaction fees have distortionary effects or cannot be implemented, and preferences are non-linear, one cannot hardly expect competition to fully discipline the market. Interestingly Ambrus and Argenziano (2003) exhibit in the case of heterogeneous populations asymmetric equilibria that involves positive profit and two active platforms. There seems to be some connection between their result and the analysis of quality choice in vertical differentiation models. In the latter case, one firm chooses a high quality, the other chooses a low quality. In two-sided markets, one can view the mass of producers as vertical quality parameter for consumers, since increasing $m$ raises the value for all consumers. Similarly $n$ is a vertical differentiation parameter for producers. One difference is that these vertical dimensions are concomitant with demand formation. In their equilibrium one platform chooses a high quality/high price on consumers ( $m$ high) and a low quality/low price on producers ( $n$ low), while the other

\footnotetext{
${ }^{21}$ Given the symmetric condition for $q$ and $p$, if $\pi>s$, the prices are $p=s-\pi, q=$ $\inf \{\pi, 2(\pi-s)\}$ leading to profit $\Pi=\inf \{s, \pi-s\}>0$.

${ }^{22}$ Passive expectations are not consistent with subgame perfection in a two-stage game where platforms set prices and then consumers and producers register. Notice however that it would be compatible with a bayesian equilibrium of the same two-stage game where each side of the market see only its prices but not the other side's prices, which seems to fit their equilibrium analysis.
} 
chooses the symmetric strategic. The platforms then achieve an endogenous vertical differentiation and therefore positive profits. The same phenomenon will be discussed in the case of multi-homing.

\subsection{Product differentiation}

Product differentiation is addressed in Jullien (2000) and Armstrong (2002). In particular, Armstrong extends the analysis by allowing horizontal differentiation. He assumes that for each side the two platforms are differentiated à la Hotelling, with the "transportation cost" being additive to the utility from transactions.

Assuming no transaction fees, and that the unit transportation costs are high enough so that both platforms are active, Armstrong concludes that equilibrium prices on both sides are below the standard Hotelling equilibrium prices (marginal cost plus unit transport cost). The interpretation of the monopoly pricing extends to this case. The standard Hotelling equilibrium prices are adjusted to include a "subsidy" for the two-sided network effects. Hence, a consumer receives a subsidy $\pi$ corresponding to the price increase that its inclusion in the network of the intermediary allows to charge on the producers. The reverse holds for producers.

This corroborates Jullien (2000) finding that two-sided network externalities reduce the equilibrium profits. In particular, intermediation platforms would benefit by being compatible as this would eliminate the two sided network effects.

\subsection{Multi-homing}

In many cases, participants to an intermediation market need not deal with only one intermediary. Fort instance, websurfers usually "surf" by using the services of several search engines or information services. By analogy with website hosting, let us refer to the fact that agent uses the services of several intermediaries as multi-homing. Notice that it is more difficult to impose exclusivity in the on-line intermediation activity compared with the brick and mortar situation, as it is easier to monitor the use of physical goods. Thus multi-homing is more likely on-line.

Caillaud and Jullien (2003) analyze the outcome of Bertrand type competition with transaction fees in this context. The main insights from the exclusivity case extend to this case. Competitive strategies can be analyzed 
as divide and conquer strategies as discussed above. The difference is that it is easier to divide since agent may join two platforms, and need not unregister from the first platform to register with the second platform. But in this context, the number of possible profitable strategies increases. Indeed a platform may try to corner the market but it may also opt for a less aggressive strategy by inducing multi-homing: the two intermediation platforms then are active and some agents register to both. Several aspects are worth mentioning.

i) With positive transaction fees, multi-homing agents will try to concentrate their activity on the low transaction fee platforms. This creates two levels of competition. Intermediaries compete to attract registration, and in a second stage they compete to attract transaction of multi-homers. This competition tends to reduce transaction fees. One should thus expect platforms to charge less transaction fees if there is a large extent of multi-homing.

ii) With imperfect intermediation activities, multi-homing may be efficient as it may allow to use a second intermediation service when one has failed to perform. So efficiency may obtain with a single active platform or two active platforms. In Caillaud and Jullien (2003), there always exists an efficient equilibrium, but profits are positive unlike the exclusivity case.

iii) The case where two platforms are active is interesting as it involves some type of endogenous vertical differentiation. In such a scenario, the platforms set different transaction fees. All agents register to both platforms and try to use the low transaction fee platform to operate their trade (the first source). They then use the service of the high transaction fee / low registration fee platform (the second source) only when they didn't find a trading on the other platform. This is reminiscent of Ambrus and Argenziano (2003) analysis. Gabszewitcz and Wauthy (2004) reach a similar conclusion on endogenous vertical differentiation in a model where producers multi-home but consumers register with one platform only. There is no transaction fees but populations are heterogeneous, and differentiation comes from different masses of agents on each platform.

iv) When some agents are multi-homing, platforms do not really compete for their registrations as the price of one platform does not affect the net gains of the agent on the other platform. Competition for these agents is then transferred either to the internal market for transaction (if the other side also multi-home), or to the other side registration market (as increased participation of the other side allows to raise the price for the multi-homing side). Some "semi-collusive" equilibrium emerges in which one side of the 
market multi-home and not the other side. Part of the profit is competed away on single-homers, but it is compensated by large registration fees for multi-homers. This type of situation, although the least efficient, may generate the highest industry profit.

\section{Tying as a coordination device}

Before concluding, let us now come back on the assumption that consumers coordinate on the positive participation level equilibrium allocation for all prices.

Consider the case of a monopoly platform. For non-negative prices, there exists an allocation where no side register. Whether agents will coordinate on the positive participation level or not depends on their beliefs about what the other side is doing. Thus beliefs matter, and agents participate only if they are confident in the participation of the others. This can be interpreted as a reputation effect. Such an interpretation in terms of reputation is developed for instance in Jullien (2000). The paper examines the optimal pricing strategy of an incumbent network challenged by a competing network, and analyzes the effect of price discrimination. The privileged position of the incumbent on the market is modeled as a reputation effect, based on the idea that each agent anticipates that others will coordinate on the incumbent or at least on the most favorable allocation for the incumbent. This is referred to as domination in beliefs. Assuming that agents coordinate on the positive demand equilibrium amounts to the same assumption.

Suppose that the intermediary has no reputation. If it wants to be sure that the consumers and the producers will join the network, it needs to set prices such that $q<F(-p) \pi$ or $p<H(-q) s$. Assume it does the former and sets the registration fees in such a way that a large enough population of consumers are willing to join even if there is no producer on the platform. Thus the intermediary has to incur significant acquisition costs for consumers, inducing a loss that is recouped with the revenue derived from the registration fees of producers or the taxation of transactions.

This strategy is referred to as "divide and conquer" (see Innes and Sexton (1993) for an application to monopoly pricing with economies of scale). One difficulty with this concept is that it leads to a payment to consumers and thus may induce agents with no perspective of trade to join. The cost may

then be huge as the intermediary may have to pay a large population to 
attract a small one. An alternative interpretation is that the payment is in kind rather than monetary.

To achieve this goal, the intermediary may tie some good or service with registration so as to create a value to registration for consumers even if producers do not participate (see below for a more detailed discussion). This interpretation is particularly attractive in the context of on-line intermediation because information goods involve mostly a fixed production cost and no distribution cost. This point is emphasized for instance in Bakos and Brynjolfsson (1999) to explain the emergence of large bundles. For our concern, what matters is that the intermediary will not be too concerned about the extra cost of subsidizing the good to consumers not interested in the intermediation activity.

Suppose that there is an overall population of consumers of size $N+1$. The mass $N$ consists of consumers who are not interested in intermediation, and face no registration costs. The mass 1 of the rest of consumers is as described before. Any subsidy to consumers would then lead the $N$ consumers to join. Suppose that the intermediary has a good to sell that can be bundled with participation. Let $v$ be the utility gain obtained by a consumer when consuming the information good proposed by the intermediary, assumed to be the same for all. Suppose that the variable cost is null. The intermediary must have some market power over the good, as otherwise the agents could obtain the full value with some competitor. Assume it is a monopoly, the profit from the sale of the good in case there is no bundling is thus $(N+1) v$.

Suppose that the firm wants to provide the intermediation service but cannot set negative registration fees for the reason exposed above. The intermediary can decide to provide intermediation tied with the information good. Then at price $(p, q)$, there will be a unique positive and active participation equilibrium if $q<F(v-p) \pi$. The total maximal profit is then

$$
\begin{aligned}
& \max _{p, q, t} p N+p n+q m+m n P(t) t, \\
& \text { st } 0<q \leq F(v-p) \pi \text { and } 0 \leq p .
\end{aligned}
$$

This will be profitable if it yields more profit than the sale of the product alone, where the cost is that the price $p$ has to be strictly lower than $v$. The condition is thus

$$
(p-v) n+q m+m n P(t) t>N(v-p) .
$$


Tie-in may help solving coordination failures generated by the two-sided nature of the market.

Turning to the case of competition, we have seen that the strategies discussed involve negative payments, in particular negative registration fees. These payments moreover are not artefact due for instance to a cost normalization. Negativity of some payments is often embedded into the nature of the strategies. Again a possible interpretation is one where the intermediary offers a gift to consumers accepting to register, or is tying some good providing a positive value. There are two alternative commercial strategies that can be used to provide some subsidies to consumers, depending on the nature of the good tied, and they will affect competition in a different manner.

In one scenario, these operations are short run commercial strategies targeted at some groups for some period of time. One may think here of advertising campaign, special offers, gifts limited in period of time, discriminatory subsidies... These fit well the above story as such strategy can be adjusted as fast as the prices. If we define the net price as $p-a$ where $a$ is the "acquisition cost" and if $a$ spend on a consumer yields $a$ units of monetary-equivalent utility, we can interpret a negative price as $a>0$ and $p=0$. The platform would then choose both $p$ and $a$, or equivalently $p-a$. However such short run strategies have limited scope.

In another scenario, the intermediary is active on several products that are offered on a permanent basis. This is for instance the case of portals, or of information sites (ZDnet). In this case, the previous analysis may not apply if the value of these additional services is large. A difference with above is that the choice of the bundle is already made when platforms decides on prices and cannot be adjusted in the short run. Remind that information goods have negligeable variable cost, so that in the case of information goods the ratio of value to price may be large. The key difference when services tied are valuable enough is that customers may be willing to stay client of a particular intermediary/seller even if there is no intermediation value, just to consume the information goods. The previous analysis argues that one of the source of profit is that producers are not willing to pay anything if consumers leave the platform. Thus there is some profit $q m$ that vanishes when the competing platform attracts consumers and this profit could not be appropriated by a competitor. This is no longer true with tying of valuable services.

Suppose that all agents receive an extra value $v$ in addition to interme- 
diation with any intermediary, with a cost $\gamma$ for the platform. First it is not clear that this will modify the nature of equilibrium prices and avoid negative prices. Consider the case with transaction fees. The profit of an active platform setting $P t=S$ is

$$
\begin{aligned}
& m n S+(p-\gamma) n+(q-\gamma) m \\
n= & F(v-p) ; m=H(v-q) .
\end{aligned}
$$

The zero profit result derived in the case of full non-distortionary taxation is still valid. Indeed setting $P t=S$ eliminates the two-sided nature of the market, and agents would simply join the lowest registration platform so that the traditional undercutting Bertrand logic applies. Still prices will be positive only if $\gamma$ is large enough, which is not the case for information goods.

Consider now the case where there is no transaction registration fee. Then in the above reasoning on the divide and conquer strategy, the registration fee for producers must convince them to give up $v$ thus (for fixed $m$ and $n$ ):

$$
\text { Conquer: } q_{2}=\pi+v+\inf \{0, q-v\}
$$

Then, provided that $q<v$, this leads to the condition that the platform 1 profit is less than $(s-\pi)$. By symmetry, whenever $p<v$, we find that the active platform profit must be less than $(\pi-s)$. But $\min \{s-\pi, \pi-s\}$ is negative so that if both prices are below $v$, both registration fees need to be negative otherwise the second platform has a profitable conquering strategy.

Indeed, as shown in Jullien (2000), if the two intermediaries tie the intermediation with other information goods, and this goods are valuable enough, the two-sided nature of the market intensifies competition. In particular, a (pure) equilibrium may not exist if the two intermediation platforms offer similar services. This suggests that intermediation markets may be unstable or "too contestable". Jullien (2000) then argues that the intermediaries can evade from competition by combining two strategies;

- Product differentiation: Intermediaries may differentiate the information goods they tie with the service. They then segment the intermediation market, focusing only on a subpopulation. This may involve strategic degradation of the quality of some services, as a commitment not to compete on some sub-segment of the population. Clearly these strategies leading to a peaceful coexistence of differentiated platforms involves inefficiencies. In particular, platforms do not exploit all the potential gains from network effects. 
- Information sharing: Differentiated intermediaries may soften competition by sharing their information and allowing their customers to access to the competitors' networks. Doing that, they reduce the importance of network effects at the platform level as they are transferred at the market level. The reason is that "divide and conquer" strategies rely on network effects within an intermediary network and they are very powerful competitive tool. By eliminating the strategic attractiveness of "divide and conquer" strategies, information sharing, and more generally compatibility between network goods, may soften competition. An example of this strategy is the increased cooperation of traditional stock markets, partly as a reaction to the emerging on-line electronic exchanges.

\section{Conclusion}

Info-mediation requires that the various sides of the market agree on using the same services. Thus the services of intermediaries on-line can be seen as a platform on which trading partners meet and interact. Such platforms are subject to two-sided network externalities, a potential source of market failure. In such a context, traditional price analysis does not apply. Intermediary should be seen as setting a price structure, and evaluating the impact of this price structure globally accounting for indirect effects. The approach of the activity in terms of two-sided markets brings some preliminary conclusions.

First pricing should and will involve some form of cross-subsidy. The service provider will attract one side of the market with a low price in order to stimulate the participation of the other one. Typically the low externality side of the market should be the target for subsidy. Competition in this context will exacerbate the tendency to cross-subsidy as competitive strategies involve a divide and conquer dimension. While ex-post concentration is likely to occur, competition should discipline the market to a larger extent than with standard isotropic network effects, although not fully. The contestable nature of such markets remains a debatable question as it seems to rely on extreme strategies that should be risky in more uncertain context.

Two questions remain to address. First it is unclear whether the nature of market failures justifies or not some regulation, and which form it would take. Second given that these markets are concentrated due to network effects, they should fall under the scrutiny of anti-trust authorities. So far the implications 
of the type of "competitive cross-subsidy" occurring in these markets for the conduct of anti-trust policy have not been properly addressed. To the least it is important that anti-trust authorities understand the economic rational of these practice and their pro-competitive effects. They should also be aware that tying with information goods may be introduced for efficiency purpose such as solving coordination problems. ${ }^{23}$

Another conclusion is that platforms should try to intervene on the design of the trading process so as to raise the total surplus from the transactions operated on the platforms. This may involve direct interventions, or some indirect effect through prices. ${ }^{24}$

Multi-homing may improve efficiency, although one should be concerned about the potential softening of competition that may result from systematic multi-homing. In particular, mandatory access to each other platform may not always be in the best interest of consumers if it leads to higher prices.

\section{References}

[1] Anderson S. and Coate S. (2003): "Market Provision of Public Good: the Case of TV Broadcasting", mimeo.

[2] Ambrus A. and Argenziano R. (2003): "Network Markets and Consumers Coordination", mimeo.

[3] Armstrong M. (2002, revised 2004): "Competition in Two-Sided Markets", UCL mimeo.

[4] Bakos and Brynjolfsson (1999): "Bundling Information Goods", Management Science.

[5] Baye M. R. and Morgan J. (2001), "Information Gatekeepers on the Internet and the Competitiveness of Homogeneous Product Markets", American Economic Review 91, No. 3, 454-474.

[6] Belleflamme P. and Toulemonde E. (2004): "Competing B2B Marketplaces", mimeo.

\footnotetext{
${ }^{23}$ See Rochet and Tirole (2004b) for a similar view on tying between two payment card services.

${ }^{24}$ See Damiano and Li (2003) for an application of this principle to asortative matching.
} 
[7] Caillaud B. and Jullien B. (2001): "Competing Cybermediaries", European Economic Review (P\&P) 45, 797-808.

[8] Caillaud and Jullien (2003): "Chicken \& Egg: competition among intermediation service providers", Rand Journal of Economics, 34, 309-328.

[9] Crampes C., Haritchabalet C. and Jullien B. (2004): "Competition with Advertising Resources", IDEI Working Paper.

[10] Damiano and Li (2003): "Pirce Discrimination in matching Markets", mimeo.

[11] Ferrando, Gabsewitcz J., Laussel D. and Sonnac N. (2003): "Two-Sided Network Effect and Competition: an Application to Media Industries", mimeo.

[12] Gabszewicz J. and Wauthy X. (2004): "Two-Sided Markets and Price Competition with Multi-homing", mimeo.

[13] Gaudeul A. and Jullien B. (2001): "E-commerce: Quelques éléments d'économie industrielle", Revue Economique 52, 97-117.

[14] Hagiu A. (2004): "Optimal Platform Pricing in Two-Sided Markets", mimeo.

[15] Innes and Sexton (1993): "Customer Coalitions, Monopoly Price Discrimination and Generic Entry Deterrence", European Economic Review 37, 1569-1597.

[16] Jullien B. (2000): "Competing with Network Externalities and Price Discrimination", IDEI Working Paper.

[17] Pashigan P. and Gould E. (1998) : "Internalizing Externalities: The Pricing os Space in Shopping Malls", Journal of Law and Economics 41, 11-142.

[18] Rochet J.C. and Tirole J. (2003): "Platform Competition in Two-Sided Markets", Journal of the European Economic Association 1, 990-1029.

[19] Rochet J.C. and Tirole J. (2004a): "Two-Sided Market: an Overview", mimeo. 
[20] Rochet J.C. and Tirole J. (2004b): "Tying in Two-Sided Market and the Honor-all-Cards Rule", mimeo.

[21] Wright J. (2003): "Optimal Card Payment System", European Economic Review 47, 587-617. 


\section{CESifo Working Paper Series}

(for full list see www.cesifo.de)

1281 Ayal Kimhi, Growth, Inequality and Labor Markets in LDCs: A Survey, September 2004

1282 Robert Dur and Amihai Glazer, Optimal Incentive Contracts for a Worker who Envies his Boss, September 2004

1283 Klaus Abberger, Nonparametric Regression and the Detection of Turning Points in the Ifo Business Climate, September 2004

1284 Werner Güth and Rupert Sausgruber, Tax Morale and Optimal Taxation, September 2004

1285 Luis H. R. Alvarez and Erkki Koskela, Does Risk Aversion Accelerate Optimal Forest Rotation under Uncertainty?, September 2004

1286 Giorgio Brunello and Maria De Paola, Market Failures and the Under-Provision of Training, September 2004

1287 Sanjeev Goyal, Marco van der Leij and José Luis Moraga-González, Economics: An Emerging Small World?, September 2004

1288 Sandro Maffei, Nikolai Raabe and Heinrich W. Ursprung, Political Repression and Child Labor: Theory and Empirical Evidence, September 2004

1289 Georg Götz and Klaus Gugler, Market Concentration and Product Variety under Spatial Competition: Evidence from Retail Gasoline, September 2004

1290 Jonathan Temple and Ludger Wößmann, Dualism and Cross-Country Growth Regressions, September 2004

1291 Ravi Kanbur, Jukka Pirttilä and Matti Tuomala, Non-Welfarist Optimal Taxation and Behavioral Public Economics, October 2004

1292 Maarten C. W. Janssen, José Luis Moraga-González and Matthijs R. Wildenbeest, Consumer Search and Oligopolistic Pricing: An Empirical Investigation, October 2004

1293 Kira Börner and Christa Hainz, The Political Economy of Corruption and the Role of Financial Institutions, October 2004

1294 Christoph A. Schaltegger and Lars P. Feld, Do Large Cabinets Favor Large Governments? Evidence from Swiss Sub-Federal Jurisdictions, October 2004

1295 Marc-Andreas Mündler, The Existence of Informationally Efficient Markets When Individuals Are Rational, October 2004 
1296 Hendrik Jürges, Wolfram F. Richter and Kerstin Schneider, Teacher Quality and Incentives: Theoretical and Empirical Effects of Standards on Teacher Quality, October 2004

1297 David S. Evans and Michael Salinger, An Empirical Analysis of Bundling and Tying: Over-the-Counter Pain Relief and Cold Medicines, October 2004

1298 Gershon Ben-Shakhar, Gary Bornstein, Astrid Hopfensitz and Frans van Winden, Reciprocity and Emotions: Arousal, Self-Reports, and Expectations, October 2004

1299 B. Zorina Khan and Kenneth L. Sokoloff, Institutions and Technological Innovation During Early Economic Growth: Evidence from the Great Inventors of the United States, 1790 - 1930, October 2004

1300 Piero Gottardi and Roberto Serrano, Market Power and Information Revelation in Dynamic Trading, October 2004

1301 Alan V. Deardorff, Who Makes the Rules of Globalization?, October 2004

1302 Sheilagh Ogilvie, The Use and Abuse of Trust: Social Capital and its Deployment by Early Modern Guilds, October 2004

1303 Mario Jametti and Thomas von Ungern-Sternberg, Disaster Insurance or a Disastrous Insurance - Natural Disaster Insurance in France, October 2004

1304 Pieter A. Gautier and José Luis Moraga-González, Strategic Wage Setting and Coordination Frictions with Multiple Applications, October 2004

1305 Julia Darby, Anton Muscatelli and Graeme Roy, Fiscal Federalism, Fiscal Consolidations and Cuts in Central Government Grants: Evidence from an Event Study, October 2004

1306 Michael Waldman, Antitrust Perspectives for Durable-Goods Markets, October 2004

1307 Josef Honerkamp, Stefan Moog and Bernd Raffelhüschen, Earlier or Later: A General Equilibrium Analysis of Bringing Forward an Already Announced Tax Reform, October 2004

1308 M. Hashem Pesaran, A Pair-Wise Approach to Testing for Output and Growth Convergence, October 2004

1309 John Bishop and Ferran Mane, Educational Reform and Disadvantaged Students: Are They Better Off or Worse Off?, October 2004

1310 Alfredo Schclarek, Consumption and Keynesian Fiscal Policy, October 2004

1311 Wolfram F. Richter, Efficiency Effects of Tax Deductions for Work-Related Expenses, October 2004 
1312 Franco Mariuzzo, Patrick Paul Walsh and Ciara Whelan, EU Merger Control in Differentiated Product Industries, October 2004

1313 Kurt Schmidheiny, Income Segregation and Local Progressive Taxation: Empirical Evidence from Switzerland, October 2004

1314 David S. Evans, Andrei Hagiu and Richard Schmalensee, A Survey of the Economic Role of Software Platforms in Computer-Based Industries, October 2004

1315 Frank Riedel and Elmar Wolfstetter, Immediate Demand Reduction in Simultaneous Ascending Bid Auctions, October 2004

1316 Patricia Crifo and Jean-Louis Rullière, Incentives and Anonymity Principle: Crowding Out Toward Users, October 2004

1317 Attila Ambrus and Rossella Argenziano, Network Markets and Consumers Coordination, October 2004

1318 Margarita Katsimi and Thomas Moutos, Monopoly, Inequality and Redistribution Via the Public Provision of Private Goods, October 2004

1319 Jens Josephson and Karl Wärneryd, Long-Run Selection and the Work Ethic, October 2004

1320 Jan K. Brueckner and Oleg Smirnov, Workings of the Melting Pot: Social Networks and the Evolution of Population Attributes, October 2004

1321 Thomas Fuchs and Ludger Wößmann, Computers and Student Learning: Bivariate and Multivariate Evidence on the Availability and Use of Computers at Home and at School, November 2004

1322 Alberto Bisin, Piero Gottardi and Adriano A. Rampini, Managerial Hedging and Portfolio Monitoring, November 2004

1323 Cecilia García-Peñalosa and Jean-François Wen, Redistribution and Occupational Choice in a Schumpeterian Growth Model, November 2004

1324 William Martin and Robert Rowthorn, Will Stability Last?, November 2004

1325 Jianpei Li and Elmar Wolfstetter, Partnership Dissolution, Complementarity, and Investment Incentives, November 2004

1326 Hans Fehr, Sabine Jokisch and Laurence J. Kotlikoff, Fertility, Mortality, and the Developed World's Demographic Transition, November 2004

1327 Adam Elbourne and Jakob de Haan, Asymmetric Monetary Transmission in EMU: The Robustness of VAR Conclusions and Cecchetti's Legal Family Theory, November 2004

1328 Karel-Jan Alsem, Steven Brakman, Lex Hoogduin and Gerard Kuper, The Impact of Newspapers on Consumer Confidence: Does Spin Bias Exist?, November 2004 
1329 Chiona Balfoussia and Mike Wickens, Macroeconomic Sources of Risk in the Term Structure, November 2004

1330 Ludger Wößmann, The Effect Heterogeneity of Central Exams: Evidence from TIMSS, TIMSS-Repeat and PISA, November 2004

1331 M. Hashem Pesaran, Estimation and Inference in Large Heterogeneous Panels with a Multifactor Error Structure, November 2004

1332 Maarten C. W. Janssen, José Luis Moraga-González and Matthijs R. Wildenbeest, A Note on Costly Sequential Search and Oligopoly Pricing, November 2004

1333 Martin Peitz and Patrick Waelbroeck, An Economist's Guide to Digital Music, November 2004

1334 Biswa N. Bhattacharyay and Prabir De, Promotion of Trade, Investment and Infrastructure Development between China and India: The Case of Southwest China and East and Northeast India, November 2004

1335 Lutz Hendricks, Why Does Educational Attainment Differ Across U.S. States?, November 2004

1336 Jay Pil Choi, Antitrust Analysis of Tying Arrangements, November 2004

1337 Rafael Lalive, Jan C. van Ours and Josef Zweimueller, How Changes in Financial Incentives Affect the Duration of Unemployment, November 2004

1338 Robert Woods, Fiscal Stabilisation and EMU, November 2004

1339 Rainald Borck and Matthias Wrede, Political Economy of Commuting Subsidies, November 2004

1340 Marcel Gérard, Combining Dutch Presumptive Capital Income Tax and US Qualified Intermediaries to Set Forth a New System of International Savings Taxation, November 2004

1341 Bruno S. Frey, Simon Luechinger and Alois Stutzer, Calculating Tragedy: Assessing the Costs of Terrorism, November 2004

1342 Johannes Becker and Clemens Fuest, A Backward Looking Measure of the Effective Marginal Tax Burden on Investment, November 2004

1343 Heikki Kauppi, Erkki Koskela and Rune Stenbacka, Equilibrium Unemployment and Capital Intensity Under Product and Labor Market Imperfections, November 2004

1344 Helge Berger and Till Müller, How Should Large and Small Countries Be Represented in a Currency Union?, November 2004

1345 Bruno Jullien, Two-Sided Markets and Electronic Intermediaries, November 2004 